\title{
FAIR VALUE HIERARCHY IN VALUATION OF INVESTMENT PROPERTIES: CONTENT ANALYSIS IN BORSA ISTANBUL
}

DOI: 10.17261/Pressacademia.2021.1493

PAP- V.14-2021(19)-p.92-96

\section{Deniz Ozbay}

Maltepe University, Faculty of Business and Management Sciences, İstanbul, Turkey denizozbay@maltepe.edu.tr, ORCID: 0000-0003-4643-7577

\section{To cite this document}

Ozbay, D., (2021). Fair value hierarchy in valuation of investment properties: content analysis in Borsa Istanbul. PressAcademia Procedia (PAP), 14, 92-96.

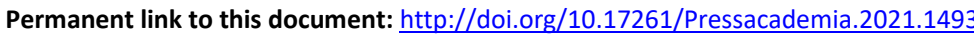

Copyright: Published by PressAcademia and limited licensed re-use rights only.

\section{ABSTRACT}

Purpose- The investment property is the most important item of the financial statements of real estate investment trusts. The valuation method of the investment properties and estimation inputs of valuation significantly affects the financial statements. This study aims to examine the level of the input used for the valuation of the investment property of the real estate investment trusts listed on Borsa istanbul. Methodology- In this study, 202 independent audit reports of 34 real estate investment trusts listed on Borsa Istanbul were analyzed with content analysis between the years 2015-2020. The level of fair value hierarchy of investment property and the trends of change over the years were calculated as frequencies. In addition, the independent audit reports of the companies included in the study were also analyzed in terms of the audit company, audit opinion and, frequency of handling of the valuation of investment property in key audit matters.

Findings- According to the findings, level 2 and then level 3 are mostly reported in the valuation of investment property. Level 1 was reported in only one company. Almost $78 \%$ of the independent audit reports examined within the scope of the study were reported by the big four companies. It has been determined that about $69 \%$ of the independent audit reports include the valuation of investment property among the key audit matters.

Conclusion. All real estate investment trusts operating in Borsa Istanbul during the review period use fair value measurement in the valuation of investment properties. While the results of previous studies indicate that level 3 inputs are mostly used in the valuation of investment properties, it has been determined that the weight of level 2 inputs has significantly increased during the review period.

Keywords: Real estate investment trusts, fair value, investment properties, audit, content analysis JEL Codes: M41, M48, M49

\section{YATIRIM AMAÇLI GAYRIMENKULLERIN DEĞERLEMESINDE GERÇEĞE UYGUN DEĞER HIYYERARŞisi: BORSA ISTANBUL'DA IÇERIK ANALIZI}

\section{ÖZET}

Amaç- Yatırım amaçlı gayrimenkuller, gayrimenkul yatırım ortaklıklarının en önemli finansal tablo kalemlerinden biridir. Yatırım amaçlı gayrimenkullerin nasıl değerlendiği ve değerlemede kullanılan tahmin girdileri finansal tabloları önemli ölçüde etkilemektedir. Çalışmanın amacı, Borsa İstanbul'a kote gayrimenkul yatırım ortaklıklarında, yatırım amaçlı gayrimenkullerin değerlenmesinde kullanılan seviye girdilerinin araştırılmasıdır.

Yöntem- Borsa İstanbul'a kote 34 adet gayrimenkul yatırım ortaklığının, 2015-2020 yılları arasındaki 202 adet bağımsız denetim raporu içerik analizi ile incelenmiştir. Yatırım amaçlı gayrimenkullerin değerlemesinde kullanılan seviyeler ve yıllar itibari ile değişim trendleri frekansalar halinde hesaplanmıştır. Ayrıca, çalışmaya dahil şirketlerin bağımsız denetim raporları denetçi firma, denetim görüşü ve kilit denetim konularında yatırım amaçlı gayrimenkullerin değerlenmesi konusunun ele alınış sıklığı açısından da analiz edilmiştir.

Bulgular- Çalışma bulgularına göre yatırım amaçlı gayrimenkullerin değerlemesinde en fazla seviye 2 ve daha sonra seviye 3 girdileri kullanılmaktadır. Seviye 1 girdilerine sadece tek bir şirkette rastlanmıştır. Çalışma kapsamında incelenen bağımsız denetim raporlarının yaklaşık \% 78'i dört büyük denetim şirketi tarafından düzenlenmiştir. İncelenen bağımsız denetim raporlarının yaklaşık \% 69'unda, yatırım amaçlı gayrimenkullerin değerlemesi konusuna kilit denetim konuları arasında yer verildiği tespit edilmiştir.

Sonuç- İnceleme döneminde Borsa İstanbul’da faaliyet gösteren gayrimenkul yatırım ortaklıklarının tamamı, yatırım amaçlı gayrimenkullerin değerlemesinde gerçeğe uygun değer ölçümünü kullanmaktadır. Geçmiş çalışmaların sonuçları yatırım amaçlı gayrimenkullerin değerlemesinde daha çok seviye 3 girdilerinin kullanıldığını belirtirken, inceleme döneminde seviye 2 girdilerinin ağırlığının önemli ölçüde arttığı tespit edilmiştir.

Keywords: Gayrimenkul yatırım ortaklıkları, gerçeğe uygun değer, yatırım amaçlı gayrimenkuller, denetim, içerik analizi JEL Codes: M41, M48, M49 


\section{Gíriş}

Yatırım amaçlı gayrimenkullerin muhasebeleştirilmesi, Türkiye Muhasebe Standartları (TMS) 40 nolu standart kapsamında ele alınmıştır. Standarda göre yatırım amaçlı gayrimenkuller, kira geliri veya sermaye kazancı ya da her ikisini birden elde etmek amacıyla elde tutulan varlıkları ifade etmektedir. Yatırım amaçlı gayrimenkuller, işletmenin sahip olduğu diğer varlıklardan büyük ölçüde bağımsız nakit akışları yaratmakta ve bu nedenle, kullanım amaçlı elde tutulan gayrimenkullerden ayırılmaktadır (TMS 40, para.7). Yatırım amaçlı gayrimenkuller, başlangıçta maliyet bedeli üzerinden ölçülürken, işletme daha sonraki ölçümlerde gerçeğe uygun değer yöntemini veya maliyet yöntemini seçme imkanına sahiptir (TMS 40, para 30). Yatırım amaçlı gayrimenkulün gerçeğe uygun değer değişiminden kaynaklanan kazanç veya kayıp, oluştuğu dönemde kâr veya zarar olarak finansal tablolara yansıtılmaktadır (TMS 40, para.35). Gerçeğe uygun değer ölçümü ise Türkiye Finansal Raporlama Standartları (TFRS) 13'te düzenlenmiştir. TFRS 13 Gerçeğe Uygun Değer Ölçümü standardı, 30.12 .2012 tarih ve 28513 sayılı resmî gazetede yayımlanmış ve 31.12.2012 tarihinden sonra başlayan hesap dönemlerinde uygulanmaya başlanmıştır. Standarta gerçeğe uygun değer, "piyasa katılımcıları arasında ölçüm tarihinde olağan bir işlemde, bir varlığın satışından elde edilecek veya bir borcun devrinde ödenecek fiyat olarak" tanımlanmaktadır (TFRS 13, para.9).

Gayrimenkul Yatırım Ortaklıklarnın (GYO) ana faaliyet konusu, gerçekleştirdikleri gayrimenkul yatırımları ile değer artış kazancı sağlamaktır. Dolayısıyla yatırım amaçlı gayrimenkuller, GYO’ların finansal tablolarında önemli bir ağırlığa sahiptir. Bu varlıkların nasıl değerlendiği de finansal tabloları önemli ölçüde etkilemektedir. Gerçeğe uygun değer tahmininde, piyasa yaklaşımı, maliyet yaklaşımı ve gelir yaklaşımından biri kullanılmakta olup, değerlemedeki amaç "mevcut piyasa koşullarında, piyasa katılımcıları arasında bir varlığın satışına veya bir borcun devrine yönelik ölçüm tarihinde gerçekleşecek olağan bir işlemdeki fiyatın tahmin edilmesidir" (TFRS 13, para. 2). Başka bir ifadeyle gerçeğe uygun değer, tahmini bir değerdir. Bu değerin tahmini ise gözlemlenebilir olan ya da gözlemlenebilir olmayan girdiler ile yapılmakta olup, tahminin mümkün olduğunca gözlemlenebilir girdilere dayanması önem arz etmektedir (TFRS 13, para. 61).

Gerçeğe uygun değer muhasebesi en çok finansal varlık ve yükümlülüklerin, maddi duran varlıkların ve yatıım amaçlı gayrimenkullerin değerlemesinde kullanılmakta olup, gerçeğe uygun değer ölçümünü benimseyen işletmelerin sayısı da günden güne artış göstermektedir. Çalışmanın amacı, Borsa İstanbul'a kote gayrimenkul yatırım ortaklıklarında, yatırım amaçlı gayrimenkullerin değerlenmesinde, TFRS 13 Gerçeğe Uygun Değer Ölçümü standardında yer alan gerçeğe uygun değer hiyerarşisinin yıllar itibariyle kullanım düzeyindeki değişimlerin tespit edilmesidir. Bu amaç doğrultusunda çalışmada ilk olarak gerçeğe uygun değer kavramı, önemi ve ölçümü konuları ele alınmış, daha sonra konu ile ilgili geçmiş bazı çalışmalar ve bulgularına yer verilmiştir. Araştırma bölümünde, Borsa İstanbul'da işlem gören GTO'ların, yatırım amaçlı gayrimenkullerini değerleme yöntemleri ve bu yöntemlerin yıllar içindeki değişimi incelenmiş ve bulgular geçmiş çalışmaların sonuçları ile karşılaştırılarak yorumlanmıştır.

\section{LITERATÜR}

Gerçeğe uygun değer muhasebesini savunanlar, gerçeğe uygun değer tahminlerinin, maliyet esasına kıyasla, daha doğru, zamanında ve karşılaştırılabilir bilgiler sağladığını iddia etmektedir (Hsu ve Wu, 2019, s.38). Finansal raporlamanın değerleme rolü söz konusu olduğunda gerçeğe uygun değer ölçümü büyük ölçüde yararlıdır, ancak bu yararlılık değişken olabilmektedir. Örneğin, uzun ömürlü işletme varlıkları söz konusu olduğunda, gerçeğe uygun değer ölçümünün güvenilirliği henüz netlik kazanmamıştır (Sellhorn ve Stier (2019). Gerçeğe uygun değer, her ne kadar finansal tablolarda görülmesi en çok arzu edilen değer olsa da ölçümü de bir o kadar zor olabilmektedir (Çetinkaya, 2017, s. 70). Çünkü, bir varlığın etkin bir piyasası bulunması halinde gerçeğe uygun değer zaten o piyasadaki değeri ifade etmektedir. Ancak etkin bir piyasanın bulunmadığı durumlarda gerçeğe uygun değer, tahmini bir fiyatı ifade etmektedir. Bu fiyat tahmininde kullanılan girdiler, gözlemlenebilir girdiler ve gözlemlenebilir olmayan girdiler olarak tanımlanmaktadır. Gerçeğe uygun değer hesaplamasında kullanılan girdilerin, mümkün olan en yüksek düzeyde gözlemlenebilir girdilerden oluşması gerekmektedir (TFRS 13, para. 61). Gerçeğe uygun değer ölçümünde kullanılan girdiler üç seviye altında açıklanmıştır (TFRS 13, para. Ek A):

Seviye 1 girdileri: İşletmenin ölçüm tarihinde erişebileceği, özdeş varlıkların veya borçların aktif piyasalardaki kotasyon fiyatları.

Seviye 2 girdileri: Varlığa veya borca ilişkin doğrudan veya dolaylı şekilde gözlemlenebilir olan, Seviye 1 içerisindeki kotasyon fiyatları dışındaki girdiler.

Seviye 3 girdileri: Varlığa veya borca ilişkin gözlemlenebilir olmayan girdiler.

TFRS 13 kapsamında yapılan seviye sıralaması, tahminlerde kullanılan farklı girdilerle ilişkili belirsizlik ve güvenilirik düzeyine dayanmaktadır (Ghio, Filip, A. ve Jeny, 2018, s. 2). Seviye 1 girdileri en güvenilir girdilerken, seviye 3 girdileri çok fazla tahmin ve belirsizlik içermesi ve dolayısıyla güvenilebilirliğinin düşük olması gerekçesi ile eleştirilmektedir. Yöneticilerin, özellikle seviye 3 kapsamındaki gerçeğe uygun değer tahminlerinde genellikle fırsatçı bir şekilde kendi takdir yetkilerini kullandığına vurgu yapan çok sayıda çalışma bulunmaktadır (Black, Chen ve Cussatt, 2021; Chen ve Wang, 2018; Chen ve Gavious, 2016).

Literatür incelendiğinde gerçeğe uygun değer hiyerarşisini konu olan çok sayıda çalışma olduğu görülmektedir. Gerçeğe uygun değer hiyerarşisiyle ilgili çoğu çalışma bankalar üzerinde gerçekleştirilmiştir. Bunun nedeni gerçeğe uygun değer ölçümünün en çok finansal varlık ve yükümlülüklerin değerlemesinde kullanılmasıdır (Hsu ve Wu, 2019, s. 44). Ghio, vd (2018), gerçeğe uygun değer üzerinde yapılan çalışmaları içeren geniş bir literatür analizi gerçekleştirmiştir. Bu çalışmada da yine bankalar üzerinde yapılan araştırmaların ağırlığı görülmektedir. Magnan, Menini ve Parbonetti (2015), 1996 - 2009 yılları arasında 309 ABD bankasından oluşan bir örneklem için yaptığı araştırmada, gerçeğe uygun değeri ile tahmin edilen varlıkların, tüm varlıkların \%22,3'ünü oluşturduğu; ayrıca, ilgili tarihlerde araştırma kapsamındaki bankaların varlık ve yükümlülüklerini \%87 oranında seviye 2 kapsamında, \% 8 oranında da Seviye 1 kapsamında raporladığı tespit edilmiştir. Xu (2019) ise, 2009-2016 yılları arasında ABD kamu bankaları üzerinde yaptığı araştırmada, gerçeğe uygun değer hiyerarşisi ile bankaların ihtiyari kredi karşılıkları arasındaki ilişkiyi analiz etmiştir. Çalışmada, seviye 2 ve seviye 3 girdilerini daha fazla kullanan 
bankaların daha az şeffaf olduğu ve kredi zararı karşılıkları konusunda daha ihtiyari oldukları sonucuna ulaşmıştır. Gökgöz ve Şentürk (2015), 2013-2014 yıllarında BIST kapsamındaki 145 adet mali kuruluşu incelemiştir. Çalışma sonuçlarına göre, mali kuruluşlar en çok finansal varlıklar ve türev ürünler ile ilgili hiyerarşi sınıflandırması yapmış olup, ağırlıklı olarak seviye 1 tespit edilmiştir. Çalışmada ayrıca, mali kuruluşlarda yatırım amaçlı gayrimenkullerin daha çok seviye 2 kapsamında raporlandığı tespit edilmiştir. Türk ve Sakin (2020), 13 bankanın $2012-2018$ yılları arasındaki gerçeğe uygun değer açıklamalarını içerik analizi ile incelenmişlerdir. Çalışmada finansal varlıkların gerçeğe uygun değerinin ağırıklı olarak seviye 1 ve seviye 2 girdileri kullanılarak raporlandığı; finansal yükümlülüklerinin değerlendirilmesinde ise ağırlıklı olarak seviye 2 girdilerinin kullanıldığı tespit edilmiştir. Özcan ve Kepçe (2021) ise, 32 mevduat bankasının 2013 - 2019 yılları arasındaki 224 adet bağımsız denetim raporunu incelemiş ve gerçeğe uygun değer hiyerarşisi ile kazanç kalıcılığı arasındaki ilşkiyi analiz etmişlerdir. Çalışma bulgularına göre, Seviye 1 girdileri ile değerlenen finansal varlıkların kazanç kalıcılığını arttırdığı, Seviye 2 girdileri ile değerlenen finansal varlıkların ise kazanç kalıcılığını düşürdüğünü göstermektedir. Seviye 3 girdileri ile değerlenen finansal varlıklar ile kazanç kalıcılığı arasında istatistiksel olarak anlamlı bir ilişki bulunamamıştır.

Yatırım amaçlı gayrimenkuller üzerinde yapılan çalışmalar ise nispeten daha azdır. Finansal varlıkların halka açık borsalarda işlem görme ve dolayısıyla kotasyon fiyatına sahip olma oranı daha fazladır. Bu nedenle gerçeğe uygun değerlerinin belirlenmesinde kullanılan girdilerin güvenilirliği daha yüksek olmaktadır. Buna karşılık, gayrimenkuller konumu, durumu ve özelliklerinin farklı olması bakımından genellikle benzersizdir. Bu durum gayrimenkul piyasasında önemli bir bilgi asimetrisine neden olmaktadır. Yatırım amaçlı gayrimenkulün gerçeğe uygun değeri, daha fazla yönetimsel tahmin, takdir veya manipülasyona açıktır. Bu yapı, bir yandan bilgi şeffaflığını kolaylaştırmak üzere kullanılabilecekken, diğer yandan varlıkların gerçek değerinin maskelenmesi için de kullanılabilir (Hsu ve Wu, 2019, s. 39). Ayrıca, yatırım amaçlı gayrimenkuller, Dünyadaki en büyük varlık sınıflarından birini temsil etmektedir. Bu nedenle değerinin ölçümündeki yanlışlıklar, finansal kararları önemli ölçüde etkileyebilme potansiyeline sahiptir (Ghosh, Liang ve Petrova, 2020, s. 206). Sundgren, Mäki ve SomozaLopez (2016), gayrimenkul şirketlerinin ağırlıklı olarak seviye 3 kapsamında gerçeğe uygun değer ölçümü yaptıklarını tespit etmiştir. Çalışmada ayrıca firmaların kurumsal alt yapılarının açıklama seviyelerini değiştirdiği sonucuna ulaşılmıştır. Çetinkaya (2017), 2009-2016 yılları arasında BiST'de işlem gören 31 adet GYO'nun yatırım amaçlı gayrimenkullerine ilişkin hiyerarşi seviyelerini analiz etmiştir. Çalışmada, şirketlerin yatırım amaçlı gayrimenkullerini \%10 oranında maliyet esasına bağlı olarak değerlediği; gerçeğe uygun değer ile ölçülen gayrimenkullerde ise en çok seviye 2 ve 3 kapsamında değerleme yapıldığı tespit edilmiştir. Cebeci ve Gökçen (2019), 2012-2018 yılları arasında BisT şirketlerinin tamamını kapsayan bir araştırma yapmıştır. Araştırmada gerçeğe uygun değer ölçümünü kullanan şirketlerin oranı \%16 olarak tespit edilirken, finansal varlıklar ve yükümlülükler ile maddi duran varlıkların ağırlıklı olarak seviye 2 kapsamında; yatırım amaçlı gayrimenkullerin ise daha çok seviye 3 kapsamında raporlandığı sonucuna ulaşılmıştır.

\section{VERI VE YÖNTEM}

Çalışma, Borsa İstanbul'da işlem gören 34 adet GYO’nı kapsamaktadır. Çalışma kapsamında, 2015-2020 yılları arasındaki 6 yılı kapsayan döneme ait 202 adet bağımsız denetim raporu içerik analizi ile incelenmiş ve yatırım amaçlı gayrimenkulleri değerleme yöntemleri analiz edilmiştir. Veriler KAP'ta (Kamuyu Aydınlatma Platformu) yer alan bağımsız denetim raporlarından elde edilmiştir.

\section{BULGULAR}

Incelenen 202 adet bağımsız denetim raporunun 70 adetinde $(\% 40,46)$ yatırım amaçlı gayri menkullerin gerçeğe uygun değeri seviye 2 girdileriyle ölçülürken, 51 adet raporda $(\% 29,48)$ seviye 3 girdilerinin kullanıldığı tespit edilmiştir. Yatırım amaçlı gayri menkullerin bir kısmının seviye 3 ve bir kısmının da seviye 2 kapsamında ölçüldüğü rapor sayısı 34 (\%19,5) iken; seviye 1 ve seviye 2 girdilerini bir arada kullanan ve tek bir işletmeye ait olan 3 adet (\%1.73) rapor bulunmaktadır. Çalışma kapsamında incelenen raporların 29 adetinde (\%16,76) yatırım amaçlı gayri menkullerin gerçeğe uygun değer ile ölçüldüğü beyan edilirken, ölçüm seviyesine ilişkin bir açıklamaya rastlanmamıştır. İncelemeye tabi şirketlerin beyan ettikleri hiyerarşi düzeylerinin yüzdesel dağılımına Grafik 1'de yer verilmiştir.

\section{Grafik 1: Hiyerarşi Seviyelerinin Yüzdesel Dağılımı}

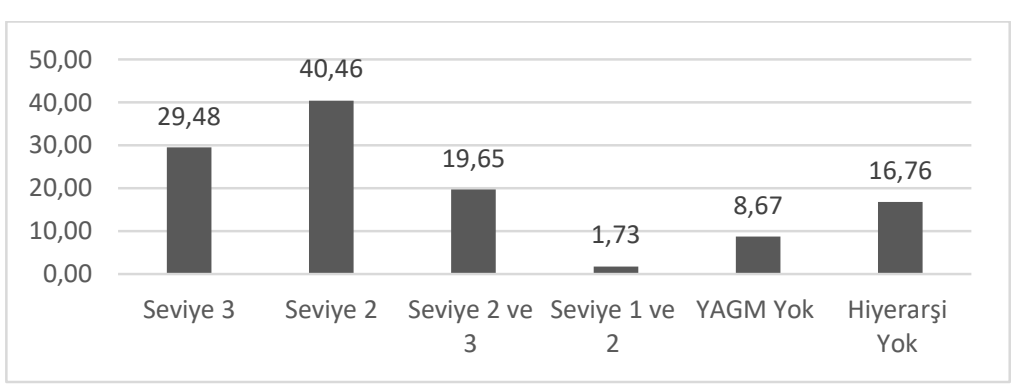

Yatırım amaçlı gayrimenkuller, aynı zamanda işletmelerin kilit denetim konularına yer verdikleri paragraflar içinde en sıklıkla raporlanan konulardan birini oluşturmaktadır (Sert ve Biçer, 2021). Kilit denetim konuları (KDK), işletmeler için önemli, kritik ve yüksek risk taşıyan konular olmaları gerekçesiyle, ülkemizde 2017 yılı bağımsız denetim raporlarından başlamak üzere, ayrı bir paragrafta sunulmaktadır. Çalışmada, yatırım amaçlı gayrimenkullerin KDK kapsamında raporlanma oranları da araştırılmış ve bulgular Garafik 2'de özetlenmiştir. Çalışma kapsamında işletmelerde 2017 yılında yatırım amaçlı gayri menkullerin değerlemesi konusunun KDK kapsamında değerlendirilme oranı \%62,86 iken, 2018 yılından bu oranın \%68,57'ye; 2019 ve 2020 yıllarında ise \%71,43'e yükseldiği görülmektedir. 
Grafik 2: Yatırım Amaçlı Gayrimenkullerin KDK iç̧inde Bildirilme Oranları

\begin{tabular}{|rrrrr|}
\hline 75,00 & 71,43 & 71,43 & & \\
70,00 & & & 68,57 & \\
65,00 & & & & 62,86 \\
60,00 & & & & \\
\hline 55,00 & & & 2018 & 2017 \\
\hline
\end{tabular}

Yatııı amaçlı gayrimenkullerin değerlenmesine yönelik olarak işletmelerin bildirdikleri girdi seviyelerinin yıllar itibariyle değişimine Garfik 3'te yer verilmiştir. Daha eski dönemleri kapsayan geçmiş çalışmaların sonuçlarından farklı olarak, incelemeye tabi tüm dönemlerde GYO'ların yatırım amaçlı gayrimenkulleri gerçeğe uygun değer ile ölçtüğü görülmüştür. En çok seviye 2 kapsamında raporlama yapılırken, seviye 3 girdileri ile raporlama yapan şirketlerin sayısı da azımsanmayacak düzeydedir. Ancak geçmiş yıllarda daha çok seviye 3 girdilerinin kullanıldığı raporlanırken; 2016 yılından itibaren en fazla seviye 2 kapsamında değerleme yapıldığı, özellikle 2018 yılından itibaren seviye 2 kapsamında yapılan değerlemelerin sayısının önemli ölçüde arttığı görülmektedir. İncelemeye tabi dönemlerde sadece tek bir şirket seviye 1 girdilerini kullanarak değerleme yaptığını beyan etmiştir.

\section{Grafik 3: Raporlanan Hiyerarşi Düzeylerindeki Değişim}

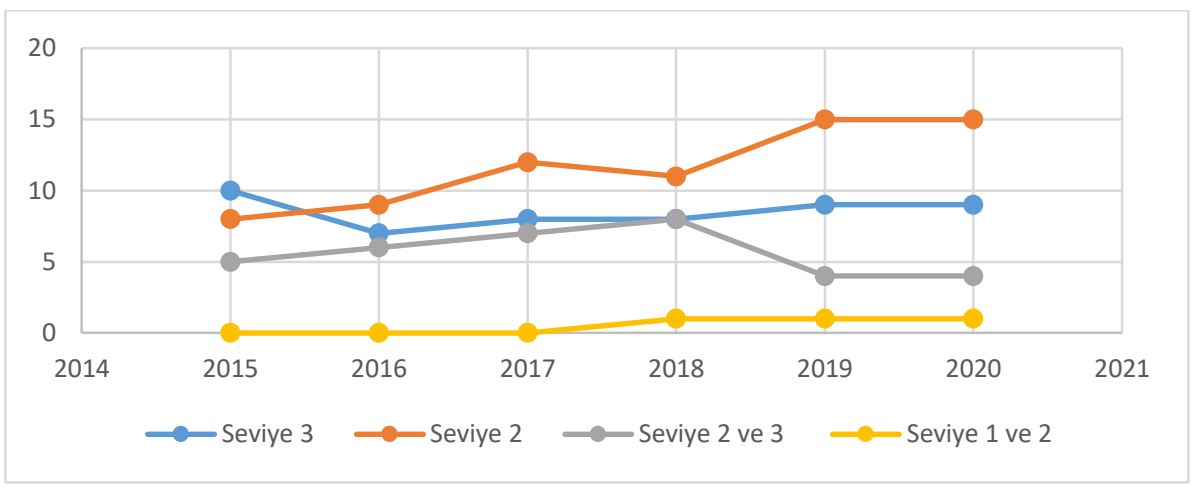

Inceleme kapsamındaki dönemlerde, maliyet temelli yaklaşımdan gerçeğe uygun değer yaklaşımına geçen şirketler olup olmadığı ayrıca incelenmiştir. 2 şirket 2016 yılı sonrası gerçeğe uygun değer ölçümünü benimsemiş ve raporlarını geçmişe dönük olarak revise ederek 2015 ylına ait de hiyerarşi bildiriminde bulunmuştur. Bu şirketlerden Kiler GYO AŞ., ilgili dönemde bu geçişe bağlı olarak, kâr veya zarar tablosunda 89.160.000 TL gelir etkisi raporlarken; Reysaş GYO AŞ.'nin de benzer şekilde 151.872.105 TL gerçeğe uygun değer değişimi raporladığı tespit edilmiştir.

İnceleme kapsamındaki GYO'ların bağımsız denetim raporları, denetim şirketi ve denetim görüşü bakımından da ayrıca incelenmiştir. Incelenen tüm bă̆ımsız denetim raporlarının yaklaşık \% $78^{\prime} \mathrm{i}$ Big Four olarak adlandırılan denetim şirketleri tarafından hazırlanmışır. Denetim raporlarında yer alan denetim görüşleri incelendiğinde çok ağırlıkıı bölümün olumlu görüş içerdiği, sadece 6 denetim raporunda şartı/sınırlı olumlu görüş beyan edilirken, 1 denetim raporunda ise görüş vermekten kaçınıldığı tespit edilmiştir. Şartlı görüş ya da görüş vermekten kaçınmayı içeren raporlarda görüş gerekçelerinden hiç biri yatııı amaçlı gayrimenkullerin değerlemesi ile ilgili değildir.

\section{SONUÇ}

Yatırım amaçlı gayrimenkuller, GYO'lar için daha fazla önem arz etmektedir. GYO'ların en önemli finansal varlıkları yatııım amaçı gayrimenkullerden oluşmaktadır. Dolayısıyla bu varlıkların değerleme yöntemi, finansal tabloları da önemli derecede etkilemektedir. Buna bağı olarak, yatırım amaçıı gayri menkullerin değerlemesinin, KDK içindeki raporlanma sıklığının yıllar itibariyle arttığı görülmüştür. Ayrıca yatırım amaçlı gayrimenkullerin değer tespitinde kullanılacak gözlemlenebilir girdilerin varlığı, finansal varlıklarda olduğundan çok daha sınırlıdır. Dolayısı ile değerleme girdilerinin daha çok seviye 2 ve seviye 3 düzeyinde olduğu görülmektedir. Bu da değerleme sonucunda oluşan fiyatın güvenilirliğini azaltmakta, fiyat tahmininde yönetim yanlılı̆ının etkisinin görülme olasılığını artırmaktadır. Geçmiş dönem çalışmaları incelendiğinde yatıım amaçı gayri menkullerini 2012 yıı sonrasında da maliyet esasına göre değerleyen GYO'ların varlı̆ı ve gerçeğe uygun değer ölçümünde en çok kullanılan seviye girdisinin seviye 3 olduğu görülmektedir. İnceleme döneminde tüm GYO’ların gerçeğe uygun değer ölçümüne geçmiş olması ve seviye 2 girdilerinin ağırlı̆̆ının önemli ölçüde artmış olması önemli bir gelişme olarak değerlendirilmiştir. Bunun yanında, inceleme döneminde maliyet temelli değerlemeden, gerçeğe uygun değer ölçümüne geçen işletmelerin bu değişime bağlı olarak kârlııklarını arttırdıkları görülmektedir. 


\section{KAYNAKÇA}

Black, J., Chen, J. Z., \& Cussatt, M. (2021). Managerial discretion and the comparability of fair value estimates. Journal of Accounting and Public Policy, (article in press)106878.

Cebeci, Y. ve Gökçen, G. (2019). Gerçeğe uygun değer hiyerarşisine ilişkin Borsa İstanbul'da içerik analizi. Journal of Research in Business. 4 (2), 196-215. DOI: 10.23892/JRB.2019.61.

Çetinkaya, N. (2017). Yatırım amaçlı gayrimenkullerin değerlemesinde gerçeğe uygun değer tespiti ve Türkiye'deki uygulamaların değerlendirilmesi. İktisadi İdari ve Siyasal Araştırmalar Dergisi, 2(4), 69-83.

Chen, E., \& Gavious, I. (2016). Unrealized earnings, dividends and reporting aggressiveness: an examination of firms' behavior in the era of fair value accounting. Accounting \& Finance, 56(1), 217-250.

Chen, M. E. N. G., \& Wang, F. S. (2018). An Empirical Study on Changes in Fair Value, Separation of Control Right and Cash flow Right and Earnings Volatility. In 2018 International Conference on Management Science and Engineering (ICMSE), 268-274.

Ghio, A., Filip, A., \& Jeny, A. (2018). Fair value disclosures and fair value hierarchy: Literature review on the implementation of IFRS 13 and SFAS 157. Paris France: Autorité des Normes Compatables.

Ghosh, C., Liang, M. \& Petrova, M. (2020). The effect of fair value method adoption: Evidence from real estate firms in the EU. The Journal of Real Estate Finance and Economics, 60(1), 205-237. https://doi.org/10.1007/s11146-019-09721-z

Gökgöz, A. ve Şentürk, F. (2015). Borsa istanbul'da işlem gören şirketlerin gerçeğe uygun değer ölçümü. Journal of Accounting, Finance and Auditing Studies. 1(4), 67-80.

Hsu, A.W., \& Wu, G.S. (2019). The fair value of investment property and stock price crash risk. Asia-Pacific Journal of Accounting \& Economics, 26(1-2), 38-63. DOI: 10.1080/16081625.2019.1545895

Magnan, M., A. Menini, \& A. Parbonetti. (2015). Fair value accounting: information or confusion for financial markets? Review of Accounting Studies, 20 (1), 559-591.

Özcan, İ. ve Kepçe, N. (2021). Gerçeğe uygun değer muhasebesinin kazanç kalıcılı̆̆ına etkisi. Mali Çözüm, 31(167), 13-38.

Sellhorn, T., \& Stier, C. (2019) Fair value measurement for long-lived operating assets: Research evidence. European Accounting Review, 28:3, 573-603, DOI: 10.1080/09638180.2018.1511816

Sert, K. ve Biçer, A. A. (2021). Gayrimenkul yatırım ortaklıklarının kilit denetim konularıyla ilişkisi. Working Paper Series, 2(1), 1-13.

Sundgren, S., Mäki, J., \& Somoza-Lopez, A. (2016). Analyst coverage, market liquidity and disclosure quality: A study of fair-value disclosures by European real estate companies under IAS 40 and IFRS 13. The International Journal of Accounting, 53(1), 54-75.

TFRS 13. Gerçeğe Uygun Değer Ölçümü. Erişim adresi:

https://kgk.gov.tr/Portalv2Uploads/files/Duyurular/v2/TMS_TFRS_Setleri/2021/Mavi_Kitap/TFRS\%2013(1).pdf

TMS 40. Yatırım Amaçlı Gayrimenkuller. Erişim adresi:

https://kgk.gov.tr/Portalv2Uploads/files/Duyurular/v2/TMS_TFRS_Setleri/2021/Mavi_Kitap/TMS\%2040(1).pdf

Türk, Z. ve Sakin, İ., (2020). Bankacılık sektöründe gerçeğe uygun değer kullanım düzeyinin tespiti. Business \& Management Studies: An International Journal, 8(4): 424-444, doi: http://dx.doi.org/10.15295/bmij.v8i4.1723

Xu, X. (2019). The association between fair value measurements and banks' discretionary accounting choices. Advances in accounting, 44 , 108-120. 